\title{
User Experience Survey for Improvement of Australia's University Campus Spatial Safe Design
}

\author{
Yunjin Wang* \\ Queensland University of Technology, Tangshan 063000, China
}

*Corresponding author: Yunjin Wang, 929999811@qq.com

\begin{abstract}
As the third vital industry supporting Australia's economic development, the education domain and related services are deserved to be emphasized. The domestic university as the major used space of the educational industry is acquiring increasingly government investments. One of the investment aspects is the improvement of safety infrastructure. By providing students and staff a convenient and safe campus experience is an effective approach to produce greater benefits. However, in most Australia universities, the safety issue is still a problem that needs to be enhanced. In this research paper, the Garden City Campus of the Queensland University of Technology is used as the case study. It will be analyzed using the methodologies of observation and survey.
\end{abstract}

Keywords: Campus safety; Observation and survey; Educational infrastructure

Publication date: July 2021; Online publication: July 31, 2021

\section{Introduction}

Recently, Australia's education industry is the major supporting domain for the Australian economy. It is recovering while playing an increasingly vital role in accelerating Australia's economic development and raising its worldwide status ${ }^{[1]}$. The related educational infrastructure and services contained in this industry are increasingly worthy to be investigated. One of the evaluated aspects is spatial safety design. Particularly in the university, the safety level impacting the users' sensations, behaviors, and decisions, further impacts the education quality, retention rate, and enrollment situation ${ }^{[2]}$. Appraising the users' engagement situation in the site is an effective approach to explicate the importance of the safe design for education industry development ${ }^{[3]}$. This research paper selects a typical Australian campus, the Gardens Point Campus of the Queensland University of Technology. Using methodologies of systematic observation to estimate its physical spatial, investigates and analyzes its spatial safe situation, and explores the benefits and drawbacks of the currently spatial safety. Crime Prevention Through Environmental Design (CPTED) is the main theoretical concepts applied in the analysis process.

\section{Background}

\subsection{University campus safety}

The crime and violence issues in university campus in the worldwide realm has been appeared for a few decades and particularly in the latter of the last century, the most country including Australia, the crime appears a significant increase ${ }^{[5]}$. Based on the past of case study about serial crimes and attacks happened in the Australian university campus, until nowadays, the reason that most university campus still exist the safety hazard is that the spatial design of these universities campus lacks the essential protection, prevention and refuges functions to protect users from the threat of unlawful activities ${ }^{[6]}$. 


\subsection{Relative Theories}

Safety theories can help designers to assess site safety comprehensively. Crime Prevention Through Environmental Design is applied in this case. Crime Prevention Through Environmental Design (CPTED) experts from different disciplines, including architects and landscape architects, start to recognize the possibly criminogenic characteristics of the environment ${ }^{[7]}$, for its intended purpose. It serves as an extra expression of ownership. This study endeavor to investigate the validity of theoretical, Crime prevention through environmental design Strategies that to what extent it might be adopted for the design process, and its effectiveness.

\section{Methodologies}

\subsection{Outline of Methodologies Application}

Initially, the concentrated aspects of the systemic observation are user behaviors, the use of the phenomenon, and their interactions related to the phenomenon. The researcher will collect related data without any direct involvement with the participants. At the stage of the observation research of this project, observers are required to attend to the target site and record relative phenomena to collect primary sources for the next analyzing stage. The whole progress of the investigation spends five weeks. The observation and survey period plan to spend two weeks and three weeks respectively. In the first two weeks, the researcher will visit the target site every day and record visitors' number and behaviors of the constant spots. The daily visiting time is 8 o'clock in the morning, 12 o'clock in the noon, and 5 o'clock in the early evening.

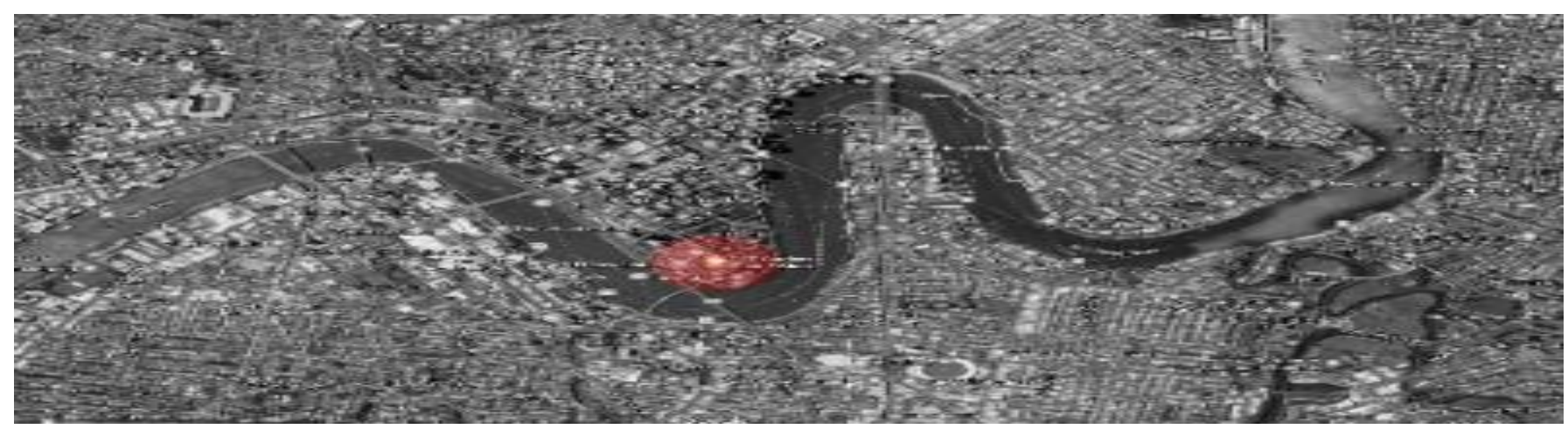

Figure 1. Map for QUT GP campus location, Brisbane, Australia ${ }^{[4]}$

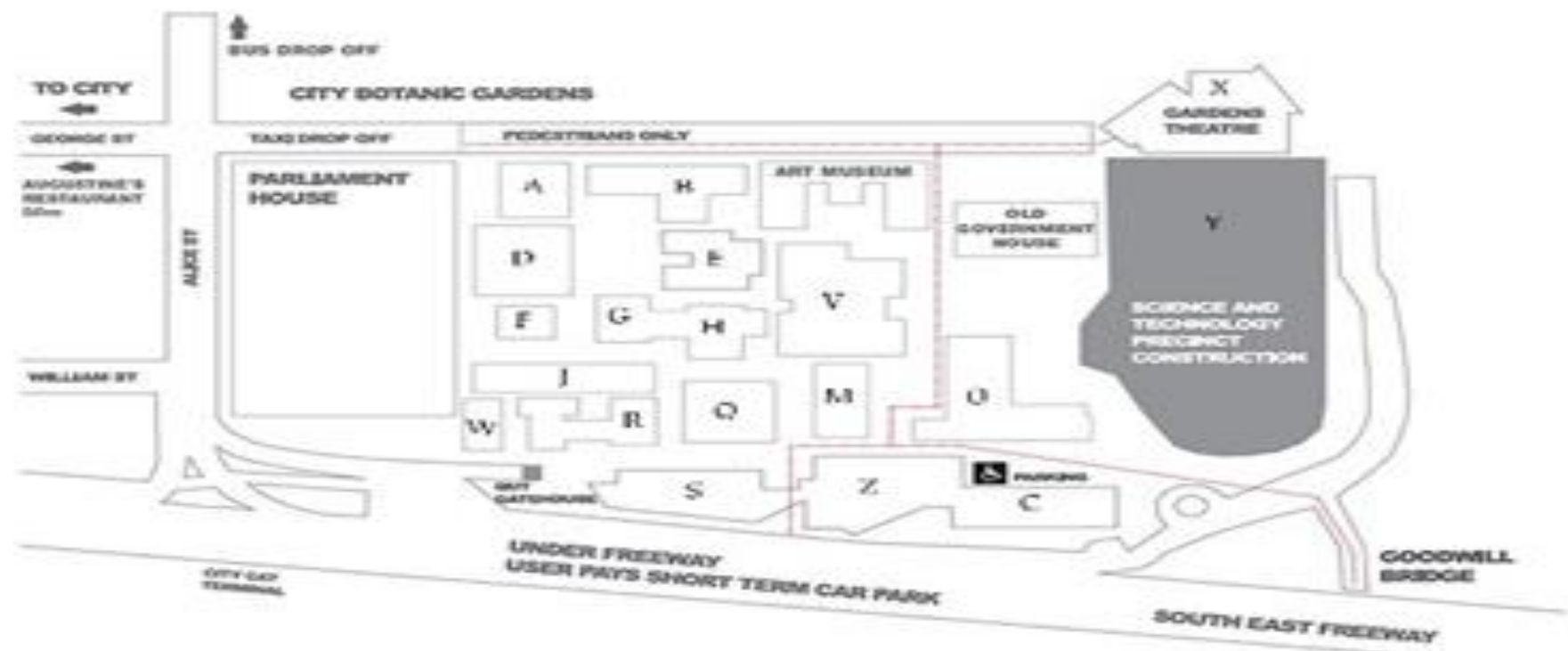

Figure 2. Map for campus observation recording base plan ${ }^{[4]}$ 


\subsection{Outcomes of observation methodologies}

Based on the influenced factors of the safety of space, the campus is divided into three aspects to systematically observe, including the use of quality, legibility and territoriality.

\subsubsection{Spatial Use - Quality}

The Space Use Quality means the frequency of users' access or stay, and their interaction level with the sites. There are three main types of districts to observe, including campus pathway, buildings access, and campus open space.

Firstly, according to the observation for campus routes, the high use of quality pathways is shown in Figure 3. They include the main drive road from the campus entrance, the wide pathways connecting to the main construction, green space and main vehicle-pedestrian shared road (Figure 3.). On the other hand, the pathways with low use quality include part secondary routes which are hidden and isolated from the main buildings, such as the V block which is the campus library (Figure 4.). The situation of use quality has a little change in three different time period.

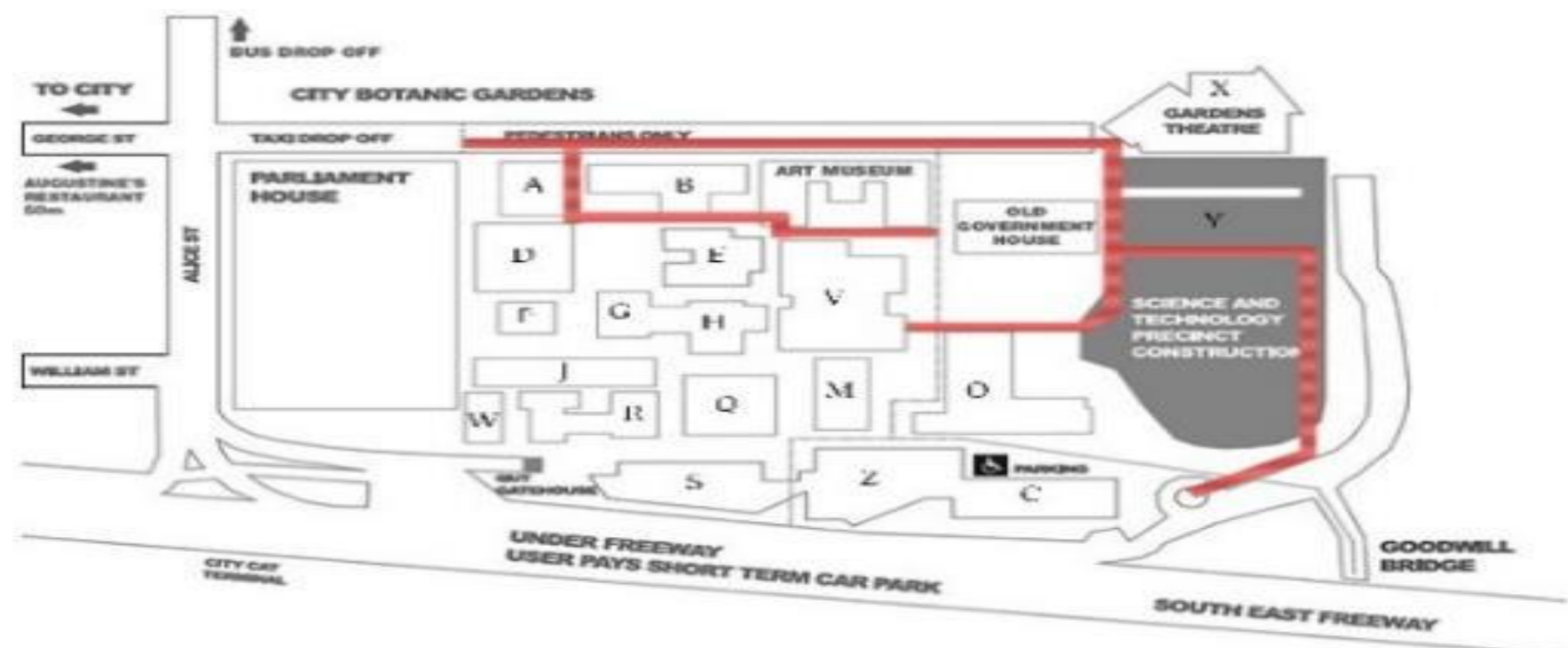

Figure 3. Mapping for high use quality pathway plan ${ }^{[4]}$

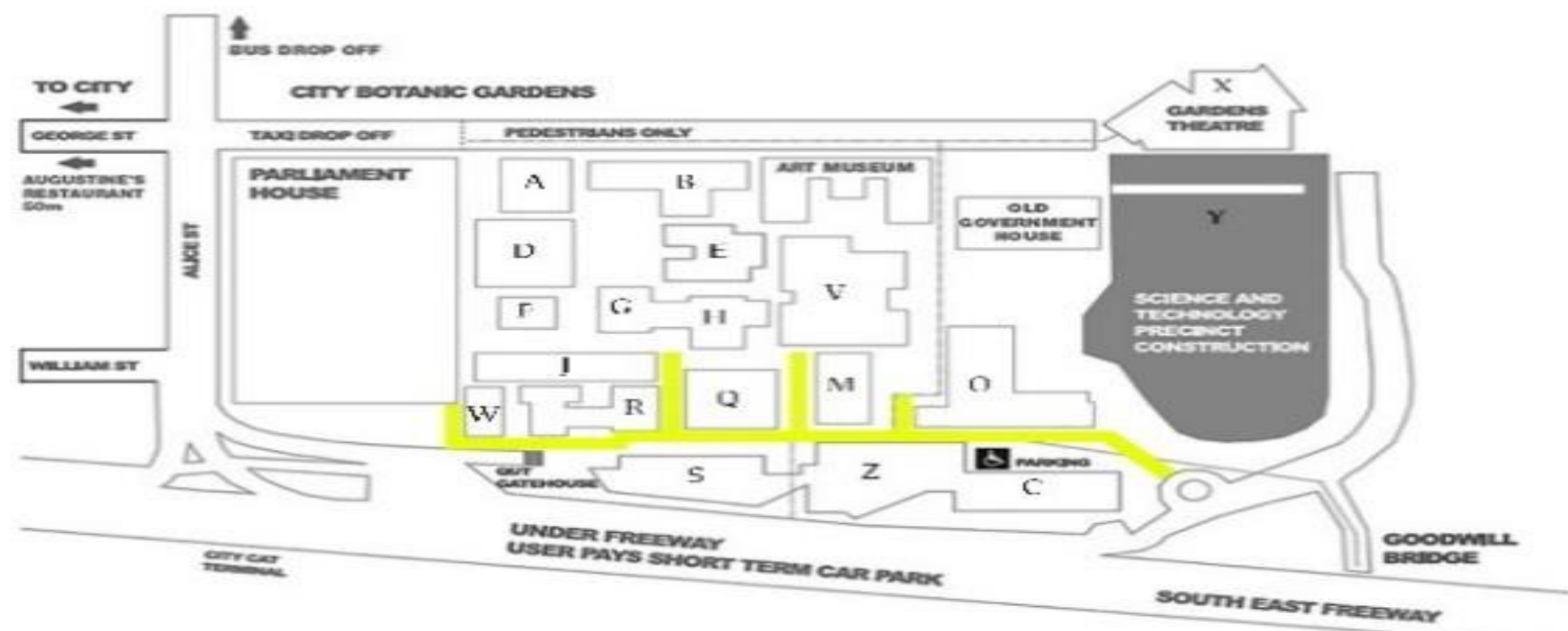

Figure 4. Mapping for low use quality pathway plan ${ }^{[4]}$ 
Secondly, building accesses with high use quality are displayed in Figure 5. It shows that the buildings locate in the central districts have high accessibility. For instance, the V block, the campus library. However, such as the $\mathrm{W}, \mathrm{R}, \mathrm{O}$, and $\mathrm{C}$ block, which buildings location is at the marginal districts of the entire campus have lower use quality (Figure 5.).

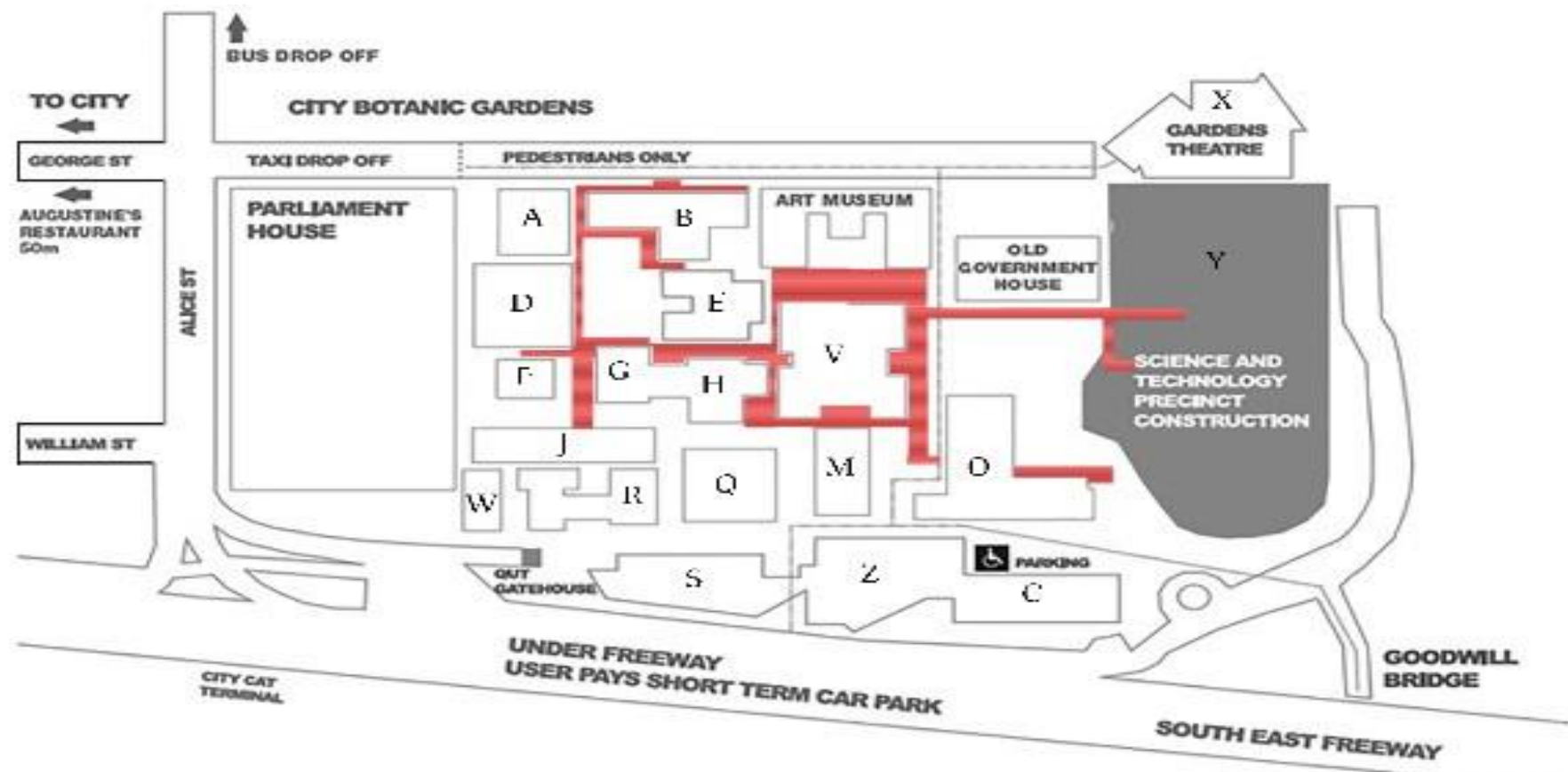

Figure 5. Mapping for high use quality building access plan ${ }^{[4]}$

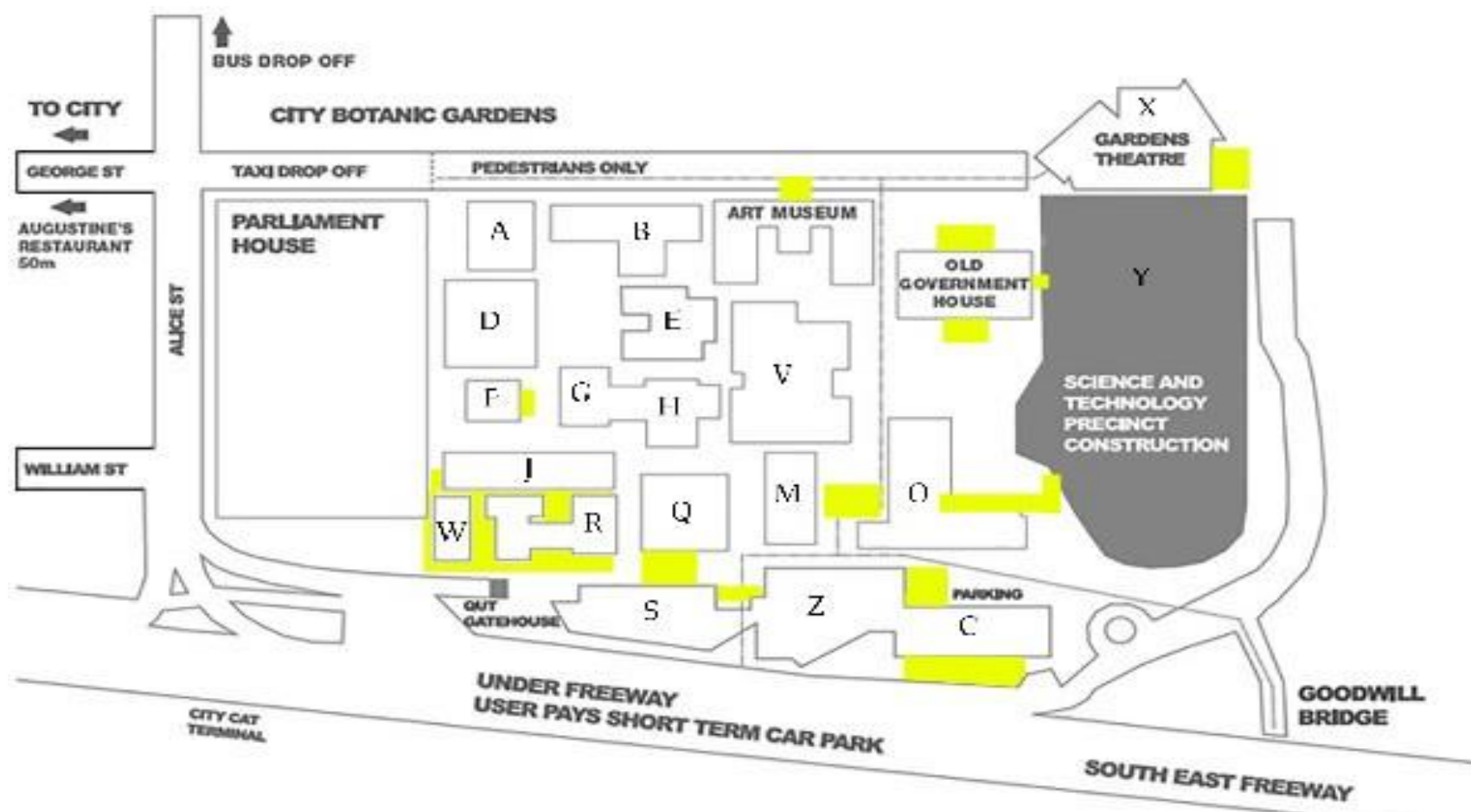

Figure 6. Mapping for low use quality building access plan ${ }^{[4]}$ 
The third aspect, campus open space with high use quality is illustrated in Figure 7. Most areas exist the features, including the settlement of benches, near sufficient shelters, and provide peaceful open views. For example, the courtyard between the D and E block. In contrast, most open space with low quality is hidden by buildings or flora groups, lack the light and infrastructure, such as the yard in front of the block $\mathrm{W}$ and the corner of the block H (Figure 8.).

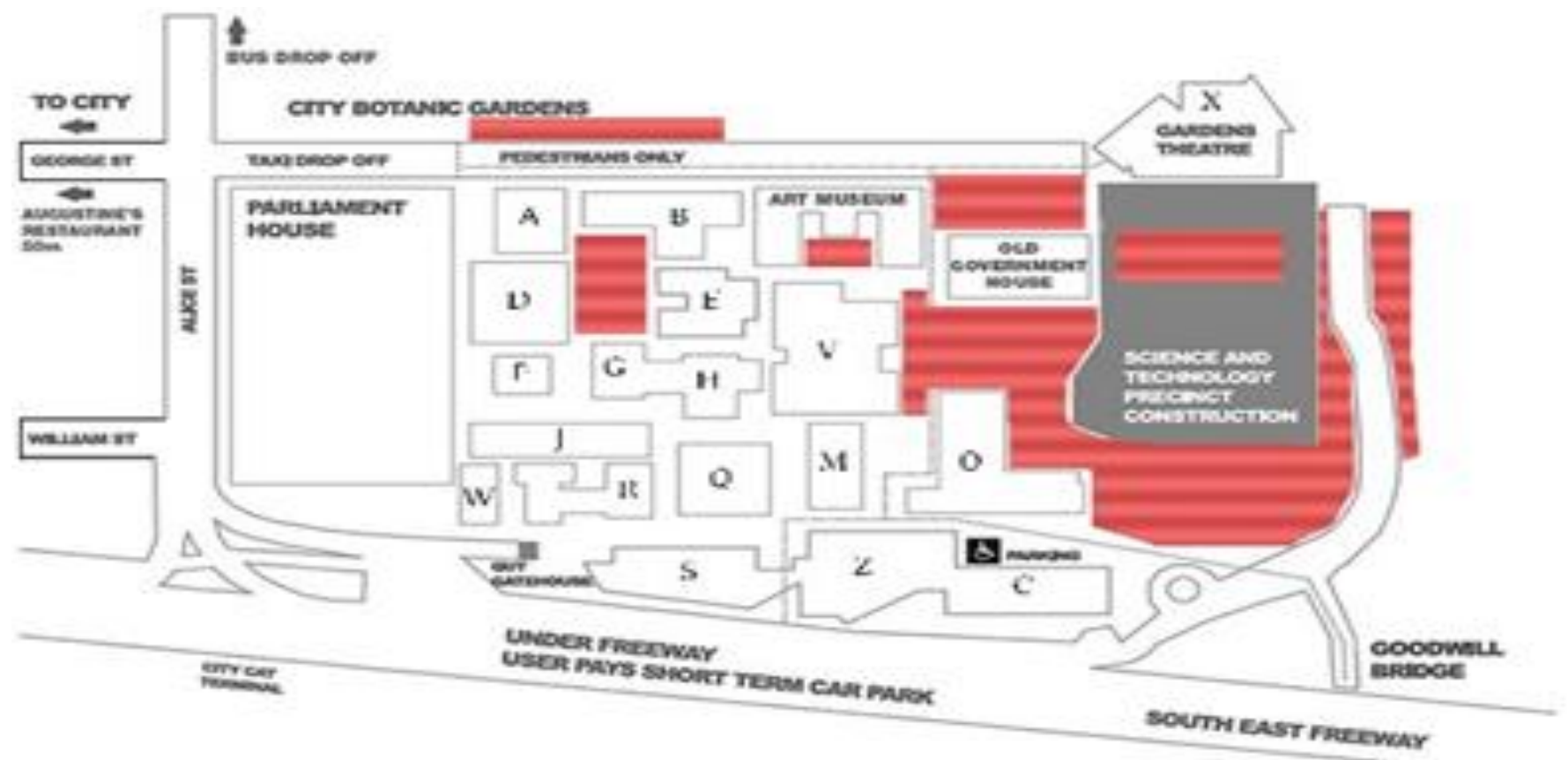

Figure 7. Mapping for high use quality open space plan ${ }^{[4]}$

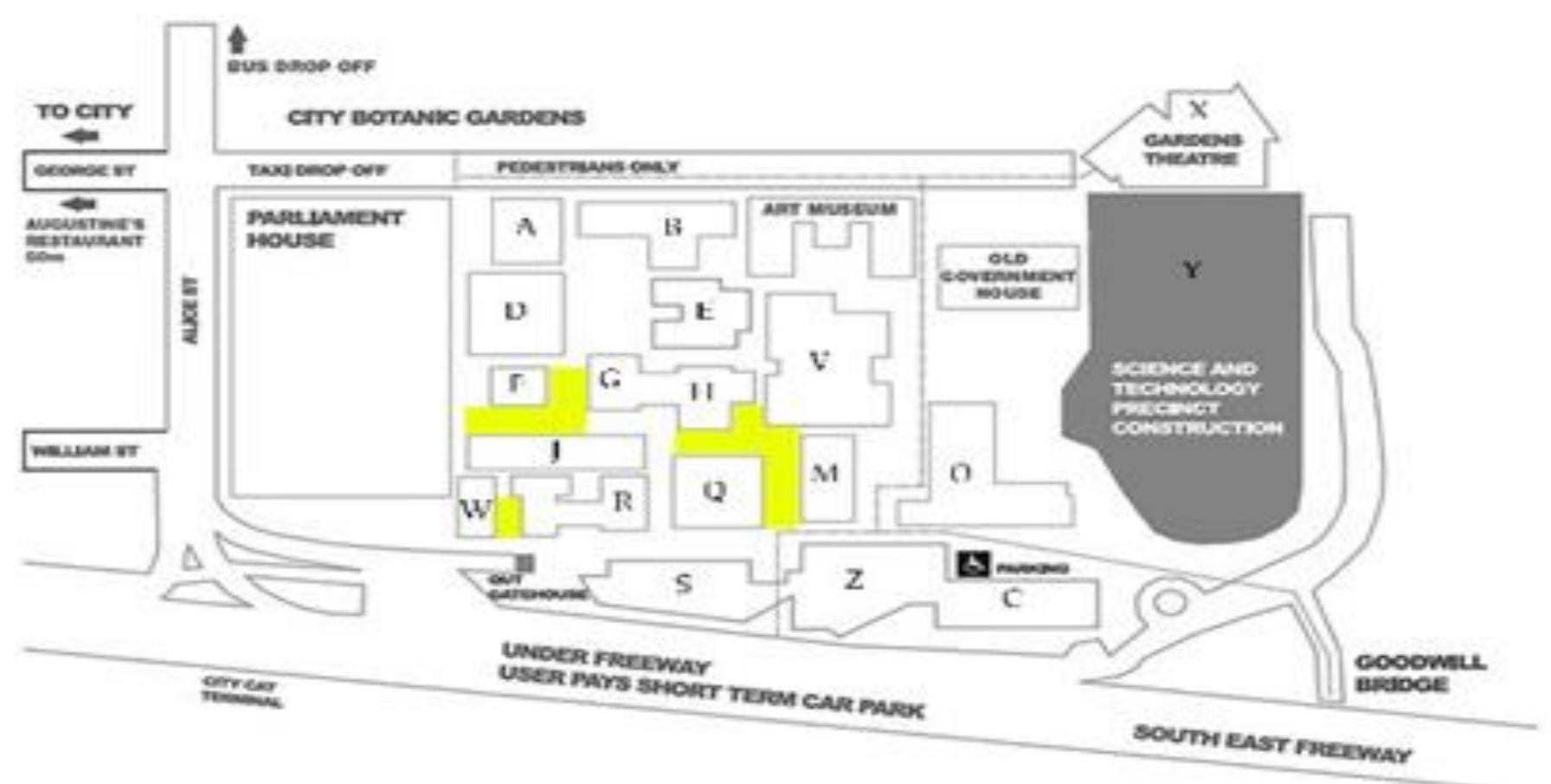

Figure 8. Mapping for low use quality open space plan ${ }^{[4]}$

\subsubsection{Place Legibility}

Place legibility is not just to enhance the users' experience, but to increase the place safety. As the 
observation for legibility includes three aspects, signage, landmarks and differentiated edges. Firstly, in this campus, there is sufficient and effective signage which can increase the legibility of the site and assist users to find their ways, even cater their needs to seeking for urgent services. For example, most outdoors and indoors signage is at noticeable locations, settling at each intersection and both roadsides. However, some of them lack clear arrows to point the orientation which makes visitors confused (Figure 9.)

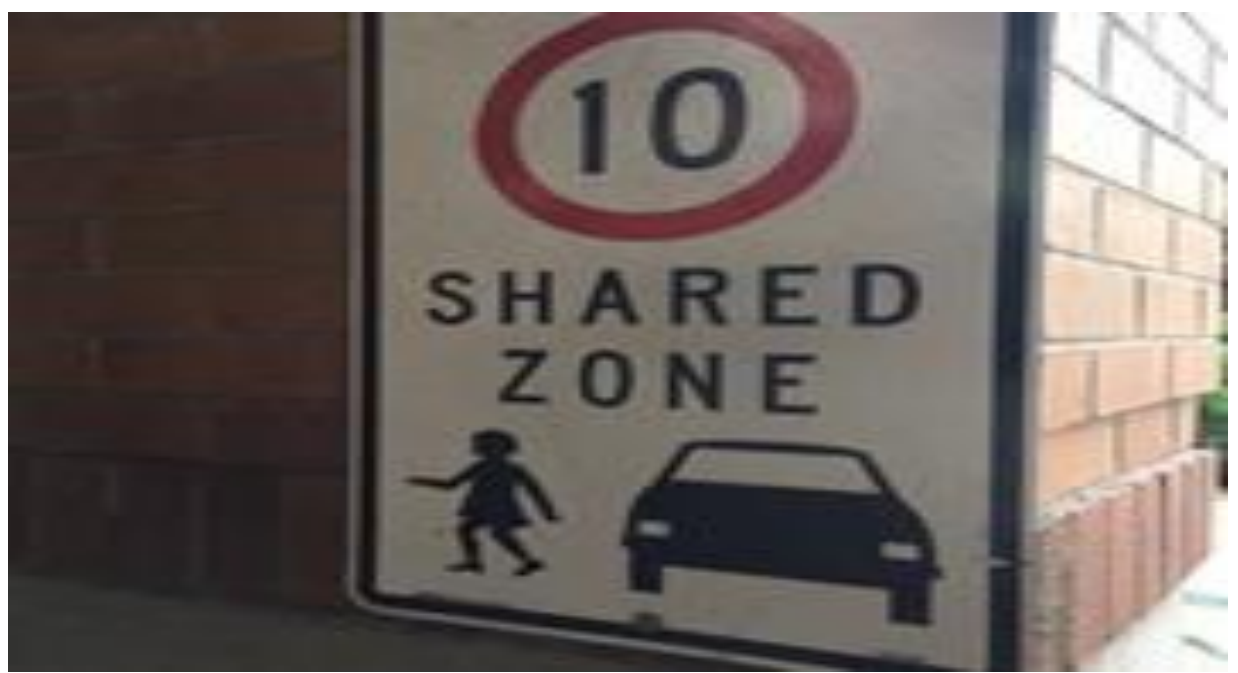

Figure 9. Campus signage ${ }^{[4]}$

The second aspect which is beneficial for improving the campus place legibility is the landmark. According to the outcomes of the site observation, there are three main types of landmarks settled on the campus, including art sculpture, graffiti wall and landscape installations (Figure 10.). They play a vital role in improving the intellectual legibility of the target place.

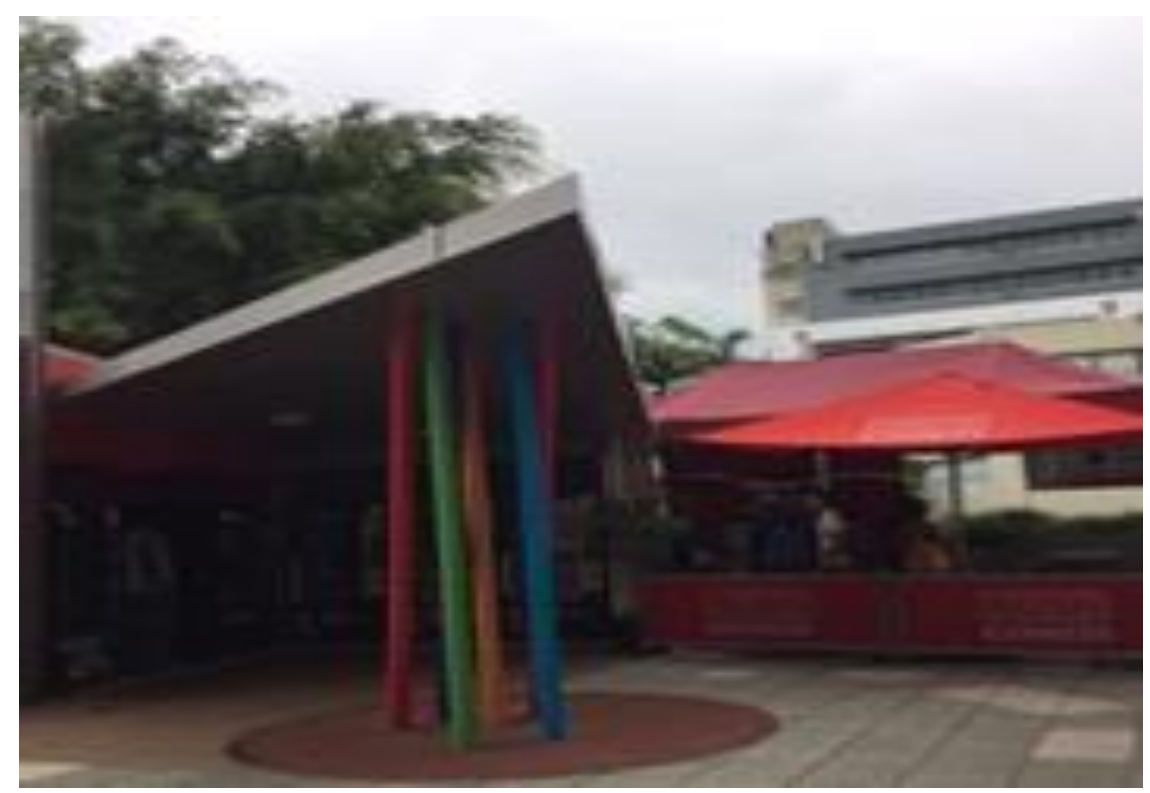

Figure 10. Campus landmarks ${ }^{[4]}$

Thirdly, in the campus, the application of the masonry curb effectively separated different districts, such as the recreation zone and planting-protection zones. Users are easy to recognize safe and unsafe areas (Figure 11.). 


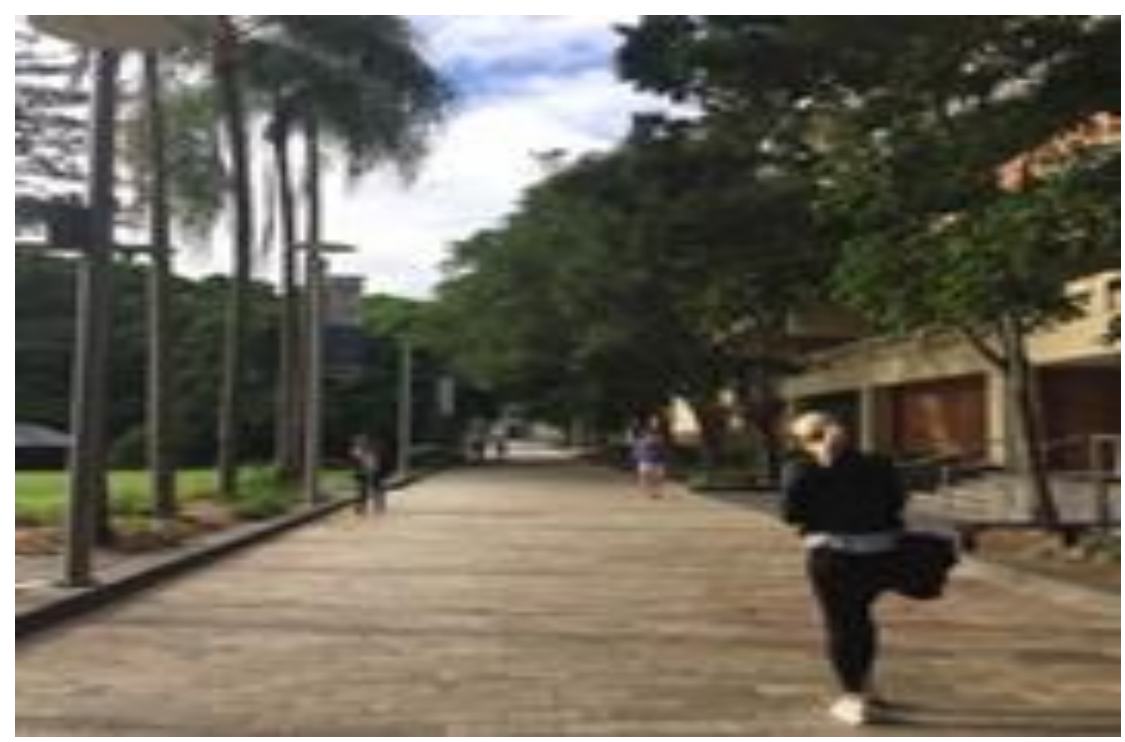

Figure 11. Campus edges with clear view ${ }^{[4]}$

\subsubsection{Campus Territoriality}

There are three main districts which are contracted by the commercial companies, campus food court and two café shops. Each district shows typical identified features of ownership (Figure 12., Figure13.). The specific expression is setting obvious logo boards and its public courtyards. It is possible that using the visualization symbols to declare territoriality and ownership of the space, can strengthen the user's trusts and safe sense to this site.

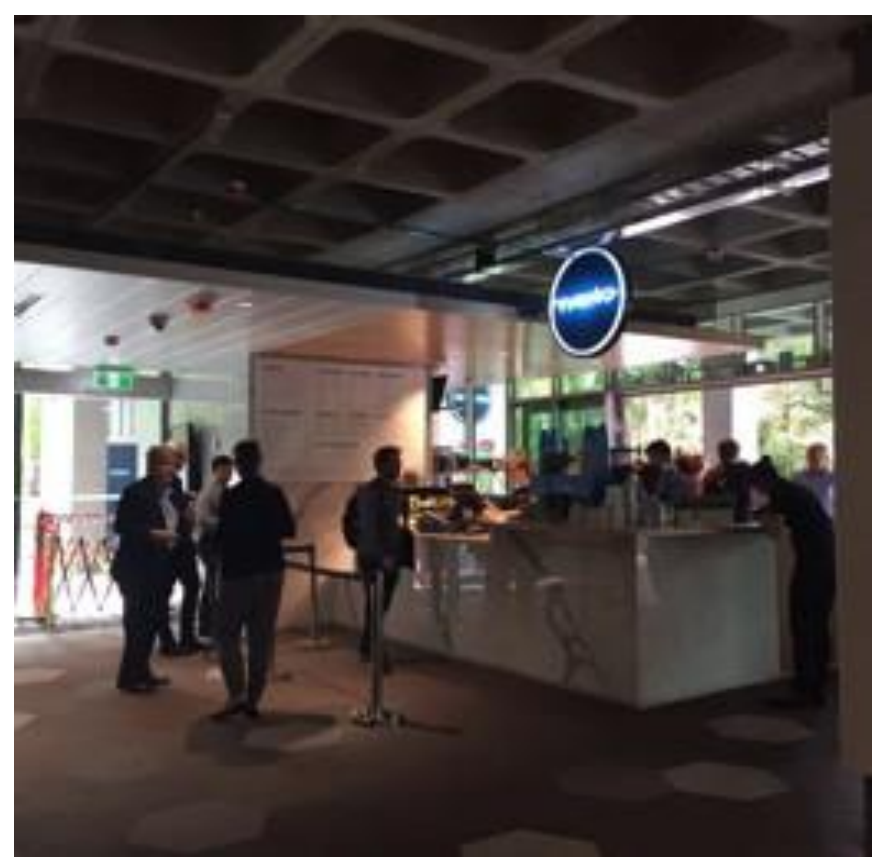

Figure 12. Campus indoor café shop with clear logo to show territoriality ${ }^{[4]}$

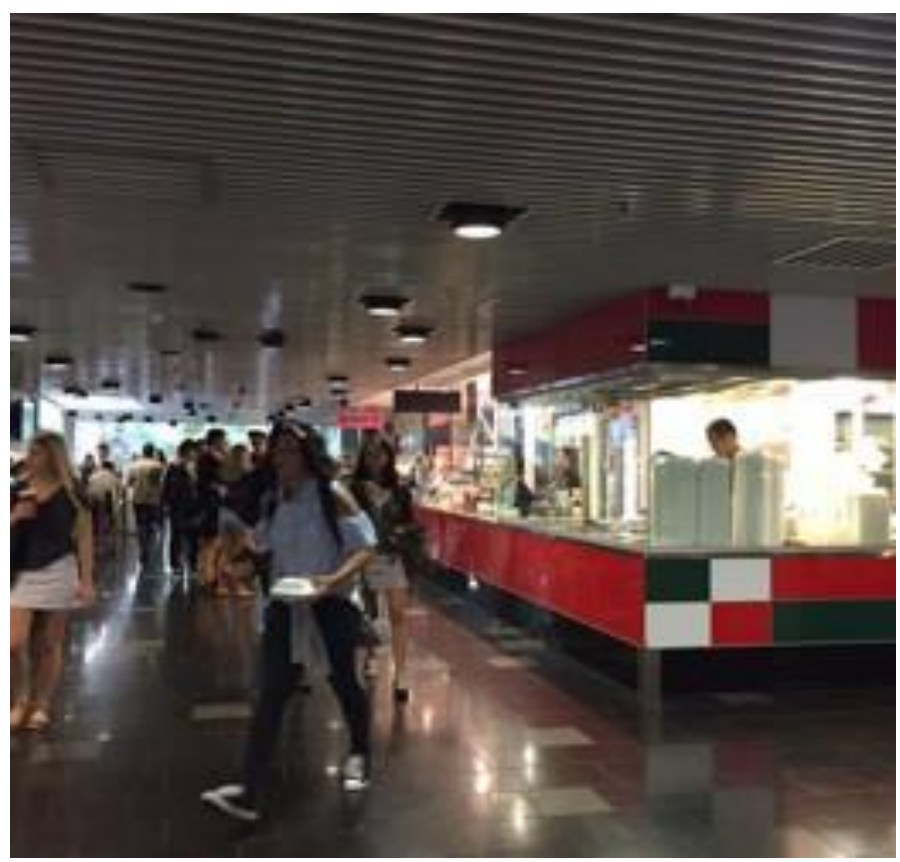

Figure 13. Campus food court with specific territoriality features ${ }^{[4]}$

\section{Findings}

Through applying observation and survey methodologies to investigate the Queensland University of Technology, Gardens Point campus, there are three main benefits and four main drawbacks. 
The first advantage is that most pathways, building access, and open space in this campus have open and wide views which provide users with a high quality of safety for experiencing. In addition, high legibility with guiding elements, path layouts, landmarks, and differentiated regions are helpful for users to find their way and in the third aspect of the security system, security personnel and camera also support to increase the safety of the site. The fourth one is that the existing territorial zones have high-quality services to provide users with a safer experience.

Nevertheless, four shortcomings also need to pay attention to. The first one is the insufficient lights for some pathways, in the night. It is possible to cause users' insecure sentiments. The second one is the design for territoriality. Some of their design exist drawbacks that cannot provide the users' enough sense of safety. The third one is the identified signage for territoriality. Partly territorial marks which might be unclear for visitor's threat user's safety. Last one, the security system on the campus should be reconnected with the users.

\section{Recommendation}

Based on the findings from data analysis, there are three design recommendations for the potential problems. They are:

(1) Increasing the numbers of campus lighting, including but not limits the streetlamps and decorative lights, while placing light sources on dark areas to play as the bright signage for the visitors passing the pathways in the night.

(2) Setting territorial signage in more noticeable places and using repeatable marks or color on their infrastructure, can strengthen the users' perceptions for territoriality.

(3) Decreasing the number of blind spots, setting more cameras to monitor and arranging more security personnel to patrol should be useful for keeping the constant watching for hidden space and avoiding accidents happening.

\section{Conclusion}

In conclusion, based on the background that the increasing crime rate in Australian university campuses, this research selects one typical domestic university as the target site to explore the application of Crime prevention through environmental design principles in the real world. According to the outcomes of the observation, the advantages in terms of use quality, legibility, territoriality, and the security system, demonstrate the improvement of safety. They are sufficiently effective and high-use quality campus space, high legibility for way-findings, and the improving campus security system. At the same time, the relevant drawbacks also display the possible threats for the users which also need to be enhanced and improved in the future, including insufficient lighting, unclear marks for the territoriality zones, as well as the lack of interactions between the campus security system information and the users. Relevant recommendations, including the improvement of campus lighting, territorial marks, and delivery efficiency of security system information to the users, will be beneficial to reduce the Australian university campus criminal rates in the future.

\section{Disclosure statement}

The author declares no conflict of interest. 


\section{References}

[1] Henderson I, et al., 2013, Worldview Australia: Australia's Education Industry is Experiencing a Recovery. ABC News Victoria. RMIT Publishing, Melbourne (Vic.).

[2] Cozens P, et al., 2019, Exploring Crime Prevention Through Environmental Design (CPTED) and Students' Fear of Crime at an Australian University Campus Using Prospect and Refuge Theory. Property Management, 37(2): 287-306. https://doi.org/10.1108/PM-04-2018- 0023.

[3] Magdy S, 2016, A Safe Space for Terrorists. British Journalism Review, 27(4): 23-28. Doi: $10.1177 / 0956474816681736$.

[4] Ha T, et al., 2015, Comparative Analysis of Defensible Space in CPTED Housing and NonCPTED Housing. International Journal of Law, Crime and Justic. 43(4): 496-511. Doi: 10.1016/j.ijlcj.2014.11.005.

[5] Wang Y, 2019, User Experience Survey for Improvement to Australia's University Campus Spatial Safe Design.

[6] VanDijk J, 2007, The World of Crime: Breaking the Silence on Problems of Security, Justice and Development Across the World. Thousand Oaks, CA: Sage.

[7] Cubbage C, Smith C, 2009, The Function of Security in Reducing Women's Fear of Crime in Open Public Spaces: A Case Study of Serial Sex Attacks at a Western Australian University. Security Journal, 22(1): 73-86. https://doi.org/10.1057/sj.2008.12.

[8] Jacobs J, 1961, The Death and Life of Great American Cities. New York: Vintage Books. 